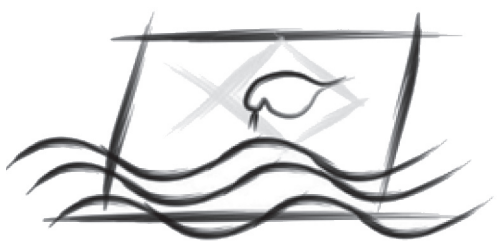

J. Braz. Soc. Ecotoxicol., v. 5, n. 1, 2010, 1-7

doi: $10.5132 /$ jbse.2010.01.001

ECOTOX - Brazil

\title{
Influência dos Métodos de Captura de Peixes na Avaliação Genotóxica Utilizando Diferentes Tecidos de Astyanax fasciatus (Osteichthyes, Characidae)
}

\author{
T. N. Moreira ${ }^{1}$, E. A. Nunes ${ }^{1}$, M. E. LeaL ${ }^{2}$, U. H. Schulz 2 \& C. T. De Lemos ${ }^{1 *}$ \\ ${ }^{1}$ Divisão de Biologia, Programa de Pesquisas Ambientais, Fundação Estadual de Proteção Ambiental \\ Henrique Luis Roessler - FEPAM, Av. Dr. Salvador França, 1707, CEP 90690-000, Porto Alegre - RS, Brasil \\ ${ }^{2}$ Laboratório de Ecologia de Peixes, Centro de Ciências da Saúde, UNISINOS, CP 275, CEP 93022-000, São Leopoldo - RS, Brasil
}

(Received June 5, 2009; Accepted November 12, 2009)

\begin{abstract}
RESUMO
Entre as abordagens para avaliar a genotoxicidade de ambientes aquáticos, peixes vêm sendo utilizados como biomonitores por reagirem sensivelmente a quaisquer alterações no meio, caracterizando-se como organismos sentinelas para biomonitoramento de rios e lagos. Os biomarcadores que refletem danos ao material genético dos peixes podem ser detectados pelo Ensaio Cometa (EC) e análise de Micronúcleos (MN), causados por diferentes agentes químicos e/ou fatores estressantes, como os originados por captura, manuseio e estocagem. Nesse estudo os métodos de tarrafa e pesca elétrica foram adotados para a captura, visando avaliar sua influência sobre a expressão dos biomarcadores utilizados em tecidos como sangue, brânquias e fígado. Indivíduos da espécie Astyanax fasciatus (Characidae) foram amostrados na lagoa dos Quadros - RS, considerada local livre de contaminação industrial, apresentando boa qualidade físico-química. Os resultados para o teste do MN, que reflete efeitos clastogênicos e aneugênicos, não mostraram diferença significante entre os métodos de captura avaliados, possivelmente por não haver tempo suficiente para a ocorrência de divisão celular, necessária para a formação de micronúcleos. Para o EC, que detecta quebras diretas ao DNA, houve diferença significante para Índice de Danos (ID) e Percentual de Danos (\%D) entre os métodos de captura em todos os tecidos analisados $(p \leq 0.001)$, indicando efeito da eletricidade nos organismos coletados.
\end{abstract}

Palavras-chave: pesca elétrica, pesca de tarrafa, estresse, genotoxicidade, micronúcleos, ensaio cometa.

\section{ABSTRACT \\ Influence of Fish Capture Methods on Genotoxic Assessment in Different Tissues of Astyanax fasciatus (Osteichthyes, Characidae)}

Among the approaches to evaluate genotoxicity of aquatic environments, fish are being used as biomonitors due to their sensitivity to any changes in the environment, characterizing it as sentinel organisms for the biomonitoring of rivers and lakes. Biomarkers that reflect damage to genetic material of fish are detected by the Comet Assay (EC) and through analysis of Micronucleus (MN) produced by different chemical agents and/or stressor factors due to capture, handling and keeping. Cast net and electric fishing were used for capture in this study, aiming to evaluate the influence of these methods on the analyzed biomarkers in different tissues, such as blood, gills and liver. Astyanax fasciatus (Characidae) individuals were captured in Quadros lagoon - RS, Brazil, site considered free on industrial contamination, showing a good physico-chemical quality. Results of MN test, which reflect clastogenic and aneugenic effects, presented no significant difference between the catch methods used, possibly because there was not enough time for cell division that is necessary for micronucleus forming. EC, which detects direct DNA brakeage, showed significant differences in Damage Index (ID) and Damage Percentage (\%D) between capture methods in all tissues examined ( $p \leq 0.001)$, indicating an effect of electricity on organisms collected.

Keywords: electrofishing, cast net, stress, genotoxicity, micronucleus, comet assay.

* Corresponding author: Clarice Torres de Lemos, e-mail: claricetl@fepam.rs.gov.br 


\section{INTRODUÇÃO}

A avaliação de genotoxicidade em ambientes aquáticos poluídos utilizando peixes como biomonitores, vem sendo amplamente utilizada em monitoramento ambiental. Estes estudos têm demonstrado a sensibilidade desses organismos na detecção de efeitos adversos provocados por contribuições antrópicas diversas (Andrade, et al., 2004; Lemos et al., 2007).

Peixes são excelentes organismos sentinelas no biomonitoramento de rios e lagos, pois estão diretamente expostos aos agressores deste compartimento ambiental, reagindo sensivelmente a quaisquer alterações no meio (Lemos et al., 2007). Apesar da dificuldade em se estabelecer ligações diretas entre efeitos ecológicos e a saúde humana, o uso de espécies da fauna nativa como sentinelas de problemas ambientais é a base conceitual para esta conexão (Silva et al., 2003).

Astyanax fasciatus (Osteichthyes, Characidae) é uma das espécies popularmente chamada como lambarí, mostrando-se frequente em rios e lagos do Rio Grande do Sul (Schulz \& Martins, 2001), tolerando inclusive, áreas com alterações significativas. Esta espécie vem se mostrando sensível em estudos genotóxicos (Lemos et al., 2008).

Os biomarcadores de genotoxicidade detectados pelo Ensaio Cometa (EC) e análise de Micronúcleos (MN), refletem danos no material genético que podem ser induzidos pelos agentes químicos presentes nas áreas estudadas (Tice, 1995).

A frequência de micronúcleos vem sendo usada como indicação rápida e sensível tanto de aberrações devido a quebras, como de perdas que levam a anormalidades cromossômicas numéricas (Heddle et al., 1991; Mateuca et al., 2006). O objetivo do teste do micronúcleo é a avaliação do potencial que as substâncias têm de causar danos cromossômicos estruturais e/ou numérico em células em estágio de divisão. Esses danos cromossômicos, geralmente estão associados com o aparecimento e/ou progressão de tumores, e com efeitos reprodutivos adversos (Ribeiro et al., 2003), o que torna importante sua detecção precoce. Dentre as principais vantagens na utilização desta metodologia estão a simplicidade, sensibilidade e rapidez de resposta, comparando-se a outros ensaios de avaliação citogenética durante a metáfase (Al-Sabti \& Metcalfe, 1995; Ayllon \& Garcia-Vazquez, 2000; Russo et al., 2004; Lemos et al., 2007).

Outro método de abordagem para avaliação genotóxica é o ensaio cometa, capaz de detectar danos no DNA induzidos por agentes alquilantes, intercalantes e oxidantes, danos esses, possíveis de serem reparados. Esse ensaio pode ser realizado tanto em animais como em plantas, demonstrando grande sensibilidade e rapidez de resultados em estudos de genotoxicidade. Ribeiro et al. (2003) salientam que esse ensaio é uma boa opção para ser utilizado em testes rotineiros in vitro e in vivo para fins de regulamentação de produtos químicos. Nos últimos anos, diversos estudos têm mostrado que micronúcleos e Anormalidades Nucleares (AN) vêm sendo usados para avaliar efeitos genotóxicas (Ayllon \& Garcia-Vazquez, 2000; Cavas \& Ergene-Gözükara, 2003). As anormalidades nucleares em geral, complementam os resultados de $\mathrm{MN}$ em pesquisas de genotoxicidade (Cavas et al., 2005).
A bibliografia tem mostrado que, alguns biomarcadores de genotoxicidade podem ter seu resultado influenciado pelo estresse causado nos organismos pelo manuseio (Lemos et al., 2001, 2007), ou sua captura (Tavares-Dias \& Moraes, 2004). No estudo de populações naturais de peixes, diretamente expostas ao agressor ambiental, é necessário empregar métodos de captura utilizando diferentes meios que poderiam provocar estresse no indivíduo.

Os métodos de coleta mais comuns são redes de espera e tarrafas, sendo que esse último tem sido a opção em diversos trabalhos, por permitirem uma retirada mais rápida dos indivíduos amostrados. O uso da pesca elétrica é uma alternativa importante, pois nesse tipo de captura é utilizado um campo elétrico, permitindo amostragens mais eficientes e menos agressivas aos organismos deixando-os por menor tempo em contato com a malha de pesca e, indicadas também, para locais onde o uso de redes e tarrafas é impróprio. Torna-se indispensável, portanto, avaliar o efeito dessa variável sobre a indução dos biomarcadores de dano genotóxicos utilizados.

Sendo assim, esse estudo objetiva avaliar a influência dos métodos de captura sobre a detecção de genotoxicidade em indivíduos da espécie $A$. fasciatus, utilizando para análise os biomarcadores Micronúcleos em sangue e Ensaio Cometa em diferentes tecidos como sangue, brânquias e fígado.

\section{MATERIAL E MÉTODOS}

O estudo foi realizado na lagoa dos Quadros, situada no litoral Norte do Rio Grande do Sul (29 $38^{\prime} 59^{\prime \prime}$ S e $\left.50^{\circ} 02^{\prime} 52^{\prime \prime} \mathrm{W}\right)$, e pertencente à bacia hidrográfica do rio Tramandaí no município de Terra de Areia (Figura 1). É uma das maiores lagoas costeiras do Estado, com área de $119 \mathrm{~km}^{2}$, profundidade média de 4,22 m. Ventos frequentes são característicos da região da lagoa, causando circulações diárias no corpo d'água resultando em níveis altos de oxigênio (Petry \& Schulz, 2000).

A escolha desse local foi motivada pelo fato de apresentar ótima qualidade físico-química (FEPAM, 2000). Essas águas estão enquadradas em classe 1 , destinadas ao abastecimento para consumo humano, após tratamento simplificado, à proteção das comunidades aquáticas e recreação de contato primário, conforme resolução CONAMA 357/2005 (CONAMA, 2005). Essas características evitam outras influências nos resultados dos testes, que não as devidas aos métodos de captura.

Foram realizados dois esforços amostrais nos meses de julho e agosto de 2007, sendo o primeiro utilizando apenas o método de tarrafa, e no segundo, a pesca elétrica. A captura dos peixes realizada por tarrafas empregou malha de $3 \mathrm{~cm}$ e, com o método da pesca elétrica, utilizou-se um gerador de corrente contínua modelo FEG 800 (EFKO, Alemanha), a $750 \mathrm{~V}$, com uma amperagem máxima de $10 \mathrm{~A}$. O procedimento é efetuado por no mínimo 3 (três) pessoas vestidas com macacões de borracha e luvas, evitando desta maneira o contato com a eletricidade, onde 2 (duas) pessoas transportam os puçás de captura e um conduz o cabo que leva a energia do gerador aos puçás, executando movimentos de vai e vem lateral.

O tempo de transporte e de repouso dos peixes nos baldes, até a realização dos ensaios, foi controlado, não ultrapassando 2 horas para o transporte e 12 horas de aclimatação, possibilitando as mesmas condições nas duas metodologias. 


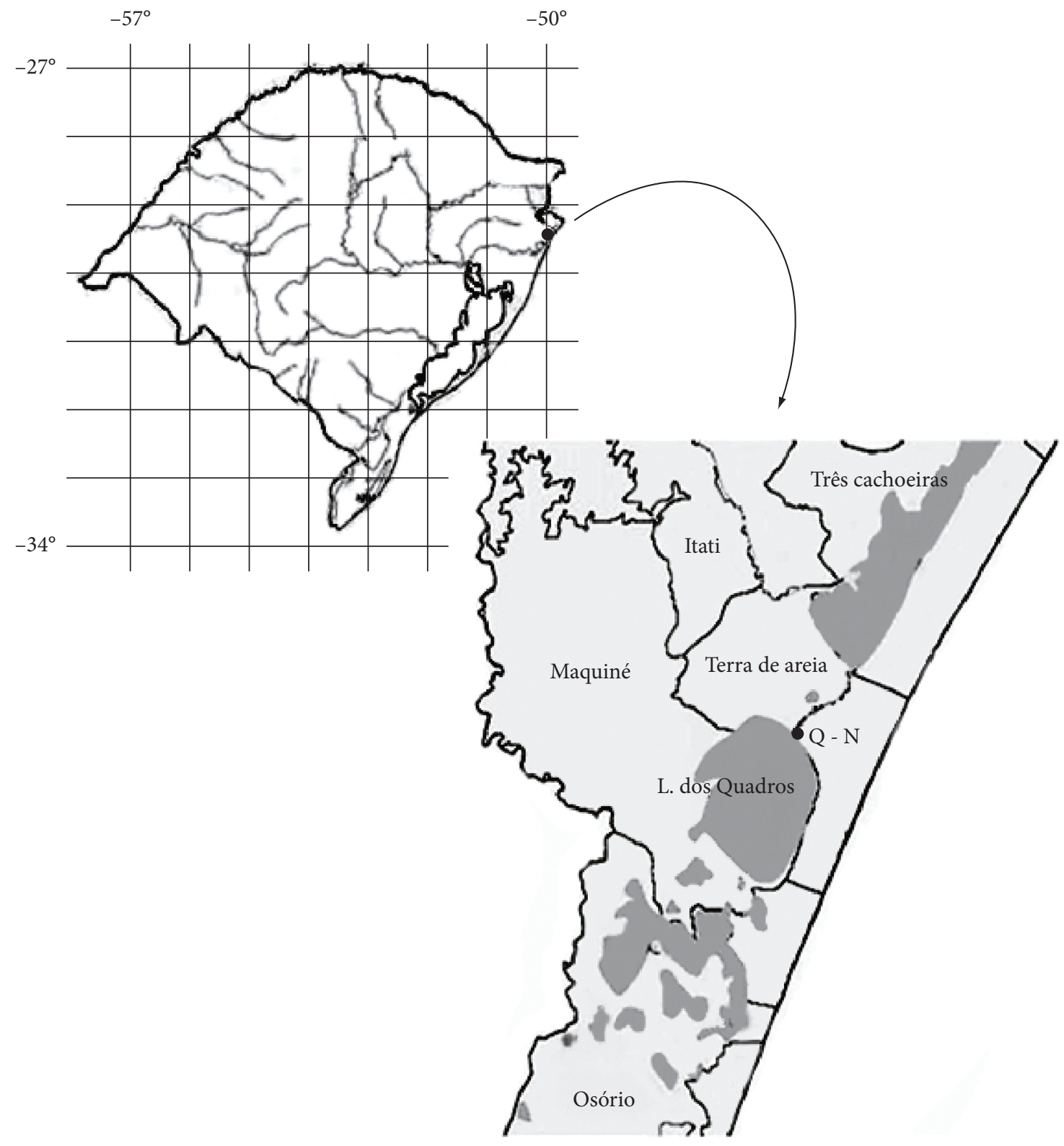

Figura 1 - Área do estudo.

\section{Análise da frequência de Micronúcleos (MN)}

O teste do micronúcleo seguiu basicamente a metodologia descrita por Lemos et al. (2001). As Anormalidades Nucleares (AN) foram identificadas seguindo os critérios de Carrasco et al. (1990) (Figura 2A-E), enquanto os MNs (Figura 2F) seguindo o critério proposto por Fenech et al. (2003).

O preparo das lâminas foi feito através de esfregaço contínuo de sangue obtido após secção cefálica e foi realizada aproximadamente entre 11 e 18 horas após a captura. As lâminas foram fixadas em metanol absoluto e coradas com Giemsa $10 \%$, por 10 minutos. Foram analisadas 2000 células por peixe em aumento $100 \times$. Na análise estatística, foi utilizado o Teste Z (Zar, 1996) para a comparação dos totais de micronúcleos, e Kruskall-Wallis para as frequências de AN consideradas em conjunto. O nível de significação foi fixado em $5 \%$.

\section{Ensaio Cometa (EC)}

Foi utilizada a versão alcalina do Ensaio Cometa, modificada a partir de Singh \& Stephens (1997), que permite a detecção de quebras simples de DNA, adutos de DNA e crosslinks. O sangue é coletado através de secção cefálica, por punção com anticoagulante heparina. O fígado e a brânquia são extraídos com auxilio de um bisturi e uma pinça, logo macerados para a obtenção das células. Imediatamente após esses procedimentos, utiliza-se $5 \mu \mathrm{L}$ de tecido diluído em $300 \mu \mathrm{L}$ de meio RPMI-1640 a $37^{\circ} \mathrm{C}$. Após o preparo, as lâminas são mergulhadas em uma solução salina contendo $20 \%$ de DMSO, com o objetivo de romper a membrana plasmática da célula, devendo remanescer sobre a lâmina apenas o núcleo para exposição às condições de eletroforese alcalina conduzida em pH 12,6, 15 V e $270 \mathrm{~mA}$, durante 20 minutos. Neutralizada em solução tampão neutra 
(pH 7,5), utilizando-se três banhos de 5 minutos cada. As lâminas são coradas com $50 \mu \mathrm{L}$ de brometo de etídeo a $20 \mu \mathrm{g} . \mathrm{L}^{-1}$. Os danos foram identificados em microscópio óptico de fluorescência, com aumento de $200 \times$, e classificados em cinco tipos, de acordo com a distância da migração do DNA rompido (classificados de T0 = célula normal, sem dano a T4 = dano máximo). Quanto maior for a distância da migração do DNA, maior a extensão do dano (Figura 3).

Foram analisadas cem células por peixe para o cálculo da Porcentagem e Índice de Dano (\%D e ID). Os parâmetros são obtidos através das equações: $[\% \mathrm{D}=100-$ número de células normais $]$ e $[\mathrm{ID}=(\mathrm{T} 0 \times 0)+(\mathrm{T} 1 \times 1)+(\mathrm{T} 2 \times 2)+$ $(\mathrm{T} 3 \times 3)+(\mathrm{T} 4 \times 4)]$. Para análise estatística foi usado o teste Kruskal-Wallis. O resultado é considerado positivo se observado diferença significante de no mínimo $p \leq 0,05$ entre os grupos estudados.

\section{RESULTADOS}

Os resultados da análise dos biomarcadores utilizados nesse estudo (MN e AN) são apresentados na Tabela 1. Foram avaliados um total de 43 indivíduos, sendo 20 capturados por tarrafa e 23 por pesca elétrica.
As frequências de $\mathrm{MN}$ em eritrócitos de peixes coletados através dos dois métodos de pesca (tarrafa $=4,7 \times 10^{-4} /$ eritrócito e pesca elétrica $=3,3 \times 10^{-4}$ /eritrócito) não apresentaram diferenças significativas $(p>0,05)$, embora tenha ocorrido um suave predomínio nos indivíduos coletados com tarrafa (Figura 4a). Portanto, o nível basal de MN apresentado por essa população de $A$. fasciatus considerando o total de indivíduos capturados foi de $4+10 \%$ célula.

Considerando o total de Anormalidades Nucleares (AN), compilando todos os tipos avaliados, verificou-se que as frequências não diferiram significantemente $(p>0,05)$ entre indivíduos capturados pelos dois métodos utilizados (Figura 4b).

No Ensaio Cometa (EC) os peixes coletados utilizando o método de pesca elétrica (Figura 5a e b) apresentaram respostas mais elevadas para ID e \%D ( $p \leq 0,001)$, em todos os tecidos analisados (sangue, brânquia e fígado).

\section{DISCUSSÃO}

Inúmeros testes têm sido desenvolvidos com organismos aquáticos visando sua utilização para avaliar os efeitos de substâncias químicas genotóxicas (Heddle et al., 1991; Al-Sabti \& Metcalfe,
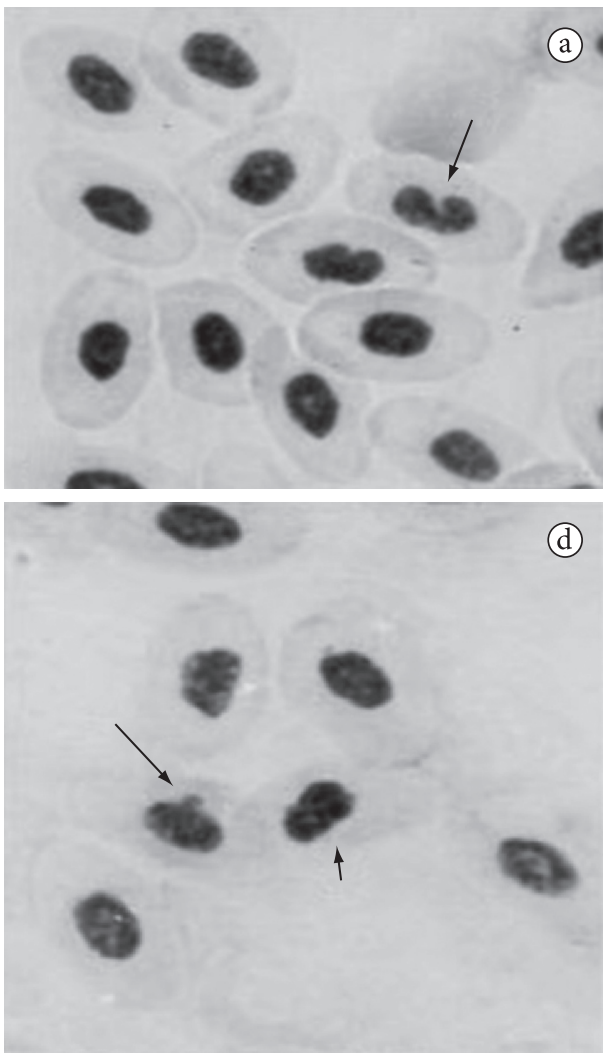

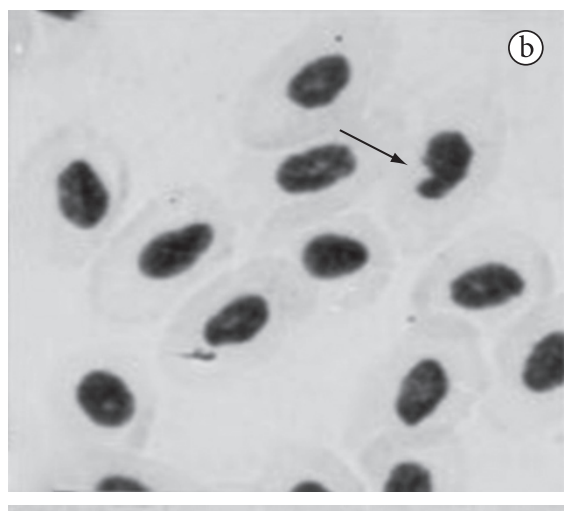

(b)

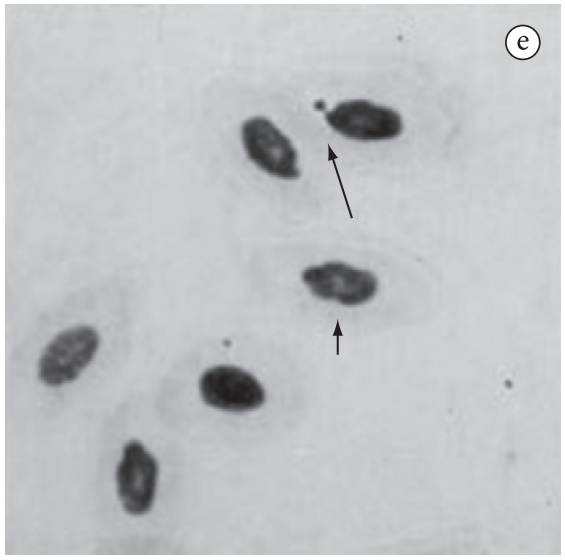

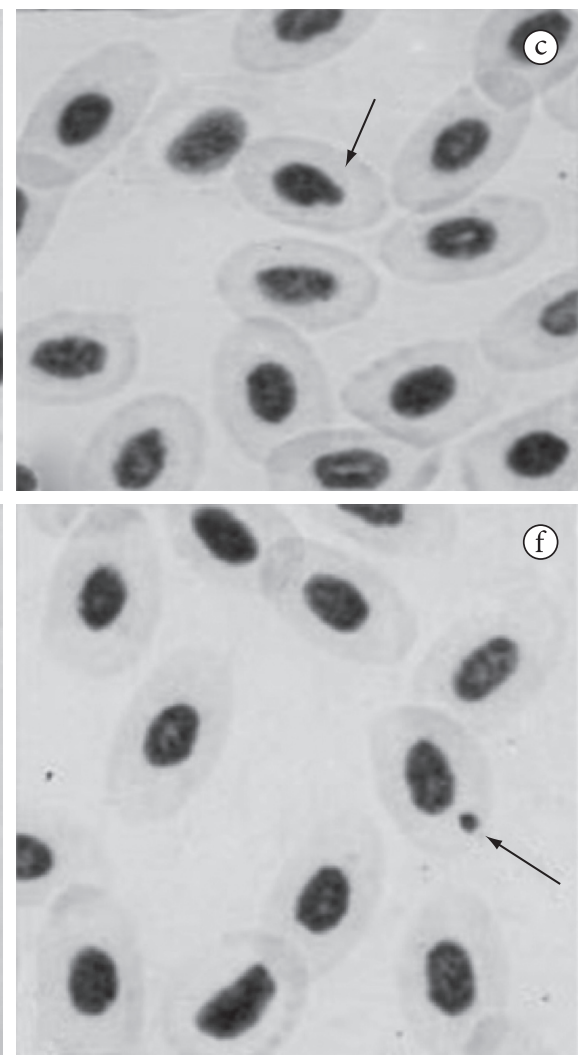

Figura 2 - Eritrócitos de peixe com presença de anormalidades nucleares (a, b, c, d, e) e micronúcleos (f), seguindo Carrasco et al. (1990).

Tabela 1 - Dados gerais sobre o número de peixes, totais e frequências de MN e AN verificados nos dois métodos de captura utilizados no estudo.

\begin{tabular}{|c|c|c|c|c|c|c|}
\hline Método & Peixes (n) & Comprimento $(\mathrm{cm})$ & MN Total & $\mathrm{MN}\left(\times 10^{-4}\right) /$ eritrócito & AN Total & $\mathrm{AN}\left(\times 10^{-4}\right) /$ eritrócito \\
\hline Pesca tarrafa & 20 & $8,3 \pm 2,1$ & 19 & 4,7 & 903 & 225,7 \\
\hline Pesca elétrica & 23 & $7,11 \pm 0,48$ & 15 & 3,3 & 1025 & 222,8 \\
\hline
\end{tabular}




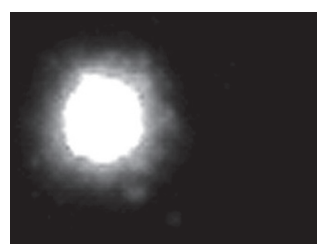

0

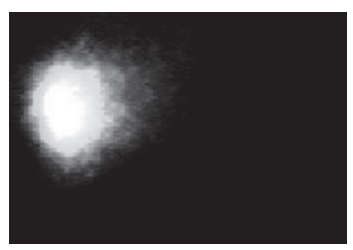

1

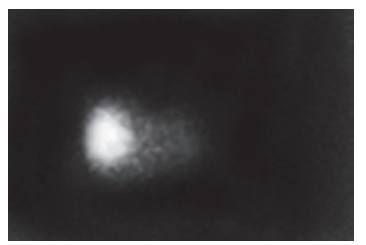

2

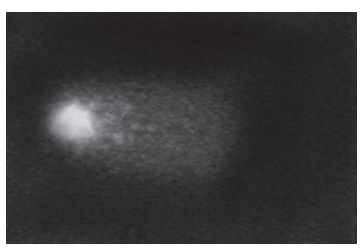

3

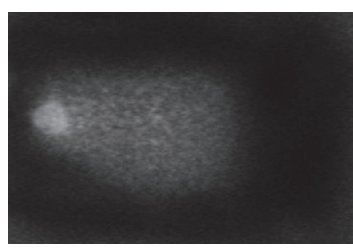

4

Figura 3 - Classes de danos variando de 0 (ausência de dano) à 4 (dano máximo).
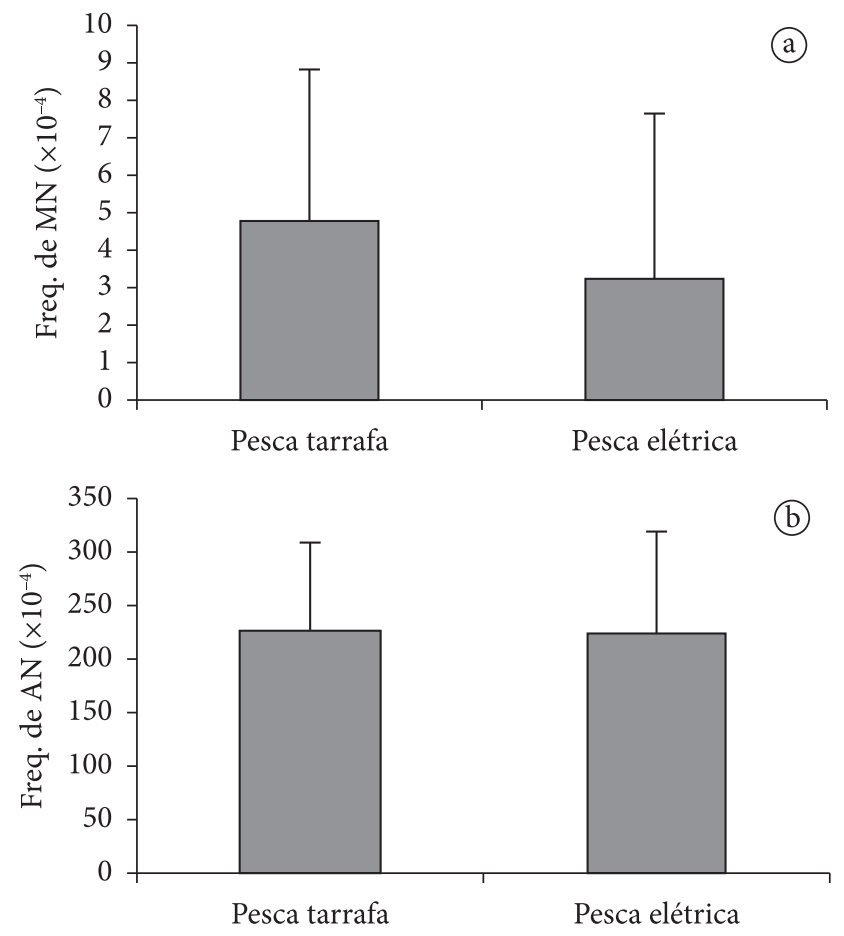

Figura 4 - Frequências de MN/eritrócito (a) e AN/eritrócito (b) observadas em peixes capturados através de dois métodos de pesca.
1995; Lemos et al., 2007, 2008). Segundo Sánchez-Galán et al. (1998), os peixes são considerados ótimos indicadores para a detecção de contaminação de recursos hídricos por substâncias genotóxicas. Eritrócitos de sangue periférico são comumente usados para a aplicação do Ensaio do Cometa em conjunto com o Teste do MN, utilizando peixes como bioindicadores para avaliação ambiental de contaminação genotóxica (Belpaeme et al., 1996; Silva et al., 2002; Buschini et al., 2004; Russo et al., 2004). Tendo em vista que, para a avaliação ambiental utilizando populações nativas de peixes, expostas in loco a agressores ambientais, a primeira etapa de trabalho é sua captura adequada, fez-se necessária a avaliação da influência desta variável nos resultados finais do estudo. Os biomarcadores, Micronúcleos e danos detectados pelo Ensaio Cometa foram utilizados neste trabalho como ferramenta de análise genotóxica cujos resultados poderiam ser influenciados uma vez que, o manuseio, captura, estoque e transporte podem causar estresse nos indivíduos induzindo danos genotóxicos (Lemos et al., 2001, 2007) e fisiológicos (Tavares-Dias \& Moraes, 2004). Nesta avaliação, comparou-se dois métodos de pesca, visando aplicá-los em biomonitoramento de mananciais de água com a essa espécie de lambaris.

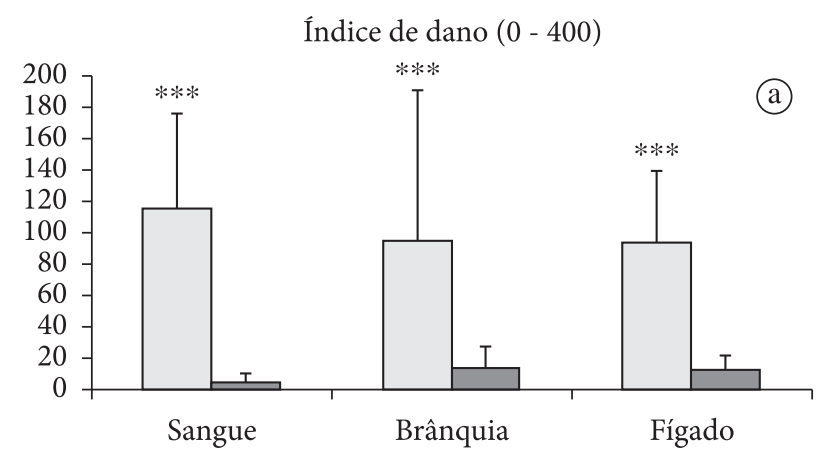

Percentual de dano

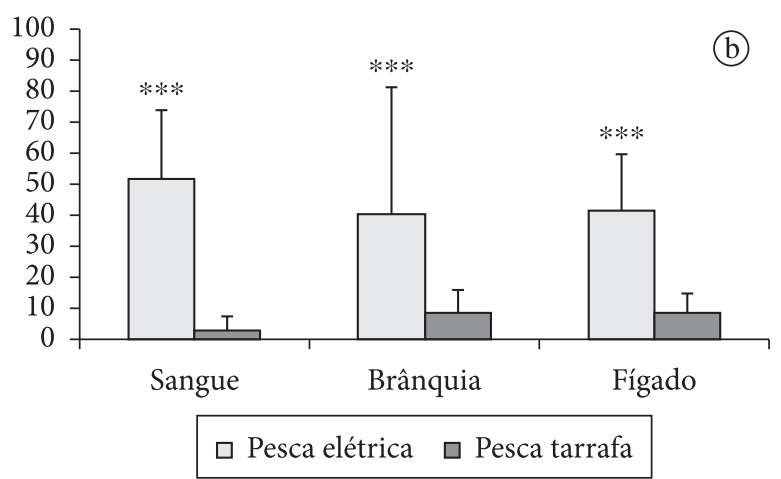

Figura 5 - Resultados do Ensaio Cometa (índice de dano (a) e Percentual de dano (b)) em células de diferentes tecidos de peixes coletados por meio de tarrafa e pesca elétrica. $* * * p \leq 0,001$.

Os resultados apresentados para o Teste do MN mostraram que não houve diferença estatística $(p \leq 0,05)$ entre os dois métodos de captura sobre a indução de $\mathrm{MN}$. Este fato poderia ser atribuído ao mecanismo de formação dos micronúcleos, que dependem da ocorrência da divisão celular após a exposição ao agente genotóxico. O tempo necessário para a ocorrência da divisão celular é dependente do tipo de tecido, da espécie que está sendo utilizada para o teste e de condições ambientais (Al-Sabti \& Metcalfe, 1995). Neste trabalho os autores reportam que, em 56 estudos de exposição a agentes genotóxicos, a duração dos testes variou de 1-58 dias, sendo que a maior expressão de MN ocorreu entre um e cinco dias. Portanto, nas condições do presente estudo com a espécie A. fasciatus, o tempo transcorrido entre a coleta dos indivíduos e a elaboração dos esfregaços sanguíneos foi insuficiente para a formação de micronúcleos.

A baixa frequência de micronúcleos $\left(4 \times 10^{-4}\right.$ /eritrócito $)$ encontrados na população estudada está dentro da faixa encontrada em outros estudos com peixes que relatam o nível basal de danos apresentado por diferentes espécies (Al-Sabti \& 
Metcalfe, 1995). Provavelmente essas variações sejam reflexos diretos da sensibilidade, do comportamento e do nicho de cada espécie (Gustavino et al., 2001).

Outro biomarcador utilizado nesse estudo, a frequência de $\mathrm{AN}$, não mostrou diferenças estatísticas significantes $(p \leq 0,05)$ entre os métodos de captura. Carrasco et al. (1990), em seus estudos com peixes, verificaram que existiam estruturas nucleares supernumerárias no citoplasma dos eritrócitos. Para tanto, classificaram as alterações nos eritrócitos como Anormalidades Nucleares (AN). Estas estruturas podem estar relacionadas a efeitos citotóxicos (Cavas et al., 2005). Efeitos agudos, como a indução de eletricidade através da pesca elétrica, podem fragilizar a membrana celular dos peixes (Tavares-Dias \& Moraes, 2004). De forma similar à formação de MN, há a dependência de um ciclo celular completo após a ocorrência do evento estressor para a detecção desse biomarcador (AN), não tendo havido tempo suficiente para o desenvolvimento do mesmo.

Em uma revisão publicada por Lee \& Steinert (2003), o Ensaio Cometa demonstrou-se vantajoso na avaliação de danos no DNA em peixes. A simplicidade e sensibilidade fazem dele um sistema adequado de teste para biomonitoramento a níveis agudos e crônicos de exposição, podendo ser utilizado em inúmeras análises onde se podem avaliar células viáveis (Belpaeme et al.,1998). Além das vantagens citadas e do relativo baixo custo, difere-se de outros ensaios que detectam danos no DNA por não requerer células em divisão, permitindo assim, sua aplicação a qualquer tipo de tecido dos quais células vivas possam ser obtidas (Collins et al., 1997; Ribeiro et al., 2003).

Concordando com estudos anteriores, neste trabalho, o Ensaio do Cometa apresentou sensibilidade, diferenciando os danos entre os dois métodos de captura em todos tecidos analisados (sangue, brânquias e fígado), apresentando diferenças significativas $(p \leq 0.001)$. Esses resultados refletem um efeito da eletricidade conduzida por corrente contínua utilizada na pesca elétrica configurando-se em um agente estressor capaz de induzir danos detectáveis pelo ensaio utilizado. Outros agentes como o confinamento, o transporte e o manejo inadequado, são alguns dos fatores citados que podem produzir estresse nos organismos (Barton \& Dwyer, 1997), e estes fatores foram controlados para não influenciar na comparação metodológica. Qualquer que seja o agente indutor, as respostas a tais estímulos são considerados alterações do equilíbrio orgânico que colocam em risco a saúde desses indivíduos, tornando-os mais susceptíveis a infecções causadas por um aumento nas taxas de cortisol. Estudos apresentam o cortisol plasmático como um indicador de estresse em peixes em qualquer que seja o estágio de desenvolvimento. A elevação desse hormônio induzido por sua captura, que é mensurado nas brânquias, intestino, e fígado refletindo alterações no controle do balanço hidromineral, do metabolismo energético (Lima et al., 2006), além de reduzir as taxas de crescimento e suprimir as funções imune e reprodutiva (Wendelaar-Bonga, 1997). Estas constatações fisiológicas confirmam efeitos do estresse provocado pela captura sobre os tecidos analisados nesse estudo.
Em mamíferos o estresse pode induzir adutos de DNA, aberrações cromossômicas e micronúcleos (Ingel et al., 1993). No presente estudo esses danos só foram detectados pelo Ensaio Cometa, podendo estar refletindo danos que podem ainda ser restaurados.

Um intervalo de tempo maior após a captura até a realização dos ensaios permitiria avaliar a detecção de micronúcleos ou a eliminação de respostas pelo ensaio cometa. Esse procedimento permitiria a evolução das necessárias divisões celulares para manifestação de $\mathrm{MN}$, AN e a confirmação dos danos, caso não reparáveis, através do Ensaio Cometa. Estudos futuros devem contemplar esta possibilidade para confirmar a não influência da pesca elétrica na indução de $\mathrm{MN}$ e para que se verifique o tempo necessário para possível reparação dos danos detectados pelo Ensaio Cometa. Essas informações são importantes, pois o método de captura de peixes utilizando eletricidade pode permitir a amostragem em locais onde não é apropriado o uso de redes e tarrafas, além de ter uma eficiência em campo comprovada. Pelo observado no presente estudo, recomenda-se que, para avaliações genotóxicas de locais com diferentes contribuições, um único método de captura seja empregado, uniformizando os efeitos dessa variável.

\section{REFERÊNCIAS BIBLIOGRÁFICAS}

AL-SABTI, K. \& METCALFE, C. D., 1995, Fish micronuclei for assessing genotoxicity in water. Mutat. Res., 343: 121-135. doi: 10.1016/0165-1218(95)90078-0.

ANDRADE, V., MANDRADE, V. M., SILVA, J., SILVA, F. R., HEUSER, V. D., DIAS, J. F., YONEAMA, M. L. \& FREITAS, T. R., 2004, Fish as bioindicators to assess the effects of pollution in two southern Brazilian rivers using the Comet assay and micronucleus test. Environ. Mol. Mutagen., 44: 459-68.

AYLLON, F. \& GARCIA-VAZQUEZ, E., 2000, Induction of micronuclei and other nuclear abnormalities in European minnow Phoxinus phoxinus and mollie Poecilia latipinna: an assessment of the fish micronucleus test. Mutat. Res., 467: 177-186. doi:10.1016/S1383-5718(00)00033-4.

BARTON, B. A. \& DWYER, W. P., 1997, Physiological stress effects of continuous- and pulsed- DC electroshock on juvenile bull trout. J. Fish Biol., 51: 998-1008. doi: 10.1111/j.10958649.1997.tb01538.

BELPAEME, K., COOREMAN, K. \& KIRSCH-VOLDERS, M., 1998, Development and validation of the in vivo alkaline comet assay for detecting genomic damage in marine flatfish. Mutat Res., 415: 167-184. doi:10.1016/S1383-5718(98)00062-X.

BELPAEME, K., DELBEKE, K., ZHU, L. \& KIRSCH-VOLDERS, M., 1996, Cytogenetic studies of PCB77 on brown trout (Salmo trutta fario) using the micronucleus test and the alkaline Comet assay. Mutagenesis, 11: 485-492. doi:10.1093/mutage/11.5.485.

BUSCHINI, A., MARTINO,A., GUSTAVINO, B., MONFRINOTTI, M., POLI, P., ROSSI, C., SANTORO, M., DÖRR, A. J. M. \& RIZZONI, M., 2004, Comet assay and micronucleus test in circulating erythrocytes of Cyprinus carpio specimens exposed in situ to lake waters treated with disinfectants for potabilization. Mutat. Res., 557: 119-129. doi:10.1016/j. mrgentox.2003.10.008.

CARRASCO, K. R., TILBURY, K. L. \& MAYERS, M. S., 1990, Assessment of the piscine micronuclei test as an in situ biological indicator of chemical contaminants effects. Can. J. Fish Aquat. Sci., 47: 2123-2136. doi:10.1139/f90-237. 
CAVAS, T. \& ERGENE-GÖZÜKARA S., 2003, Micronuclei, nuclear lesions and interphase silver-stained nucleolar organizer regions (AgNORs) as cyto-genotoxicity indicators in Oreochromis niloticus exposed to textile mill effluent. Mutat. Res., 538: 81-91. doi:10.1016/S1383-5718(03)00091-3.

CAVAS, T., GARANKO, N. N. \& ARKHIPCHUK, V. V., 2005, Induction of micronuclei and binuclei in blood, gill and liver cells of fishes subchronically exposed to cadmium chloride and copper sulphate. Food Chem. Toxicol., 43: 569-574. doi:10.1016/j. fct.2004.12.014.

COLLINS, A. R., DOBSON, V. L., DUSINSKÁ, M., KENNEDY, G. \& STETINA, R., 1997, The comet assay: what can it really tell us? Mutat. Res., 375:183-193. doi:10.1016/S00275107(97)00013-4.

CONAMA, Conselho Nacional do Meio Ambiente, 2005, Resolução $N^{\circ} 357$ - 17 de março de 2005. Conselho Nacional do Meio Ambiente, Brasília, DF.

FENECH, M., CHENG, W. P., KIRSCH-VOLDERS, M., HOLLAND, N., BONASSI, S. \& ZEIGER, E., 2003, HUMN project: Detailed description of the scoring criteria for the cytokinesis-block micronucleus assay using isolated human lymphocyte cultures. Mutat. Res., 534: 65-75. doi:10.1016/ S1383-5718(02)00249-8.

FEPAM, Fundação Estadual de Proteção Ambiental, 2000, Diretrizes Ambientais para o Desenvolvimento dos Municípios do Litoral Norte. Porto alegre, 53p.

GUSTAVINO, B., SCORNAJENGHI, K. A., MINISSI, S. \& CICCOTTI, E., 2001, Micronuclei induced in erythrocytes of Cyprinus carpio (teleostei, pisces) by X-ray and colchicine. Mutat. Res., 494: 151-159. doi:10.1016/S1383-5718(01)00191-7.

HEDDle, J. A., CIMINO, M. C., HAYASHI, M., ROMAGNA, F., SHELBY, M. D., TUCKER, J. P., VAPARYS, P. H. \& MACGREGOR, J. I., 1991, Micronuclei as an index of cytogenetic damage: Past, present, and future. Environ. Mol. Mutagen., 18: 277-291. doi: 10.1002/em.2850180414.

INGEL, F. I., GEVORKIAN, N. M., ILIUSHINA, N. A., LEITINA, B. I., PRIKHOZHAN L. M., PEREVERZEVA, E. L. \& REVAZOVA, I. A., 1993, Prolonged psychoemotional stress as an inducer of mutation in mammals and as a modifier of mutagenesis. Bull. Exp. Biol. Med., 116: 307-309.

LEE, R. F. \& STEINERT, S. 2003, Use of the single cell gel electrophoresis/comet assay for detecting DNA damage in aquatic (marine and freshwater) animals. Mutat. Res. 544: 43-64. doi:10.1016/S1383-5742(03)00017-6.

LEMOS, C. T., IRANÇO, F. A., OLIVEIRA, N. C. D., SOUZA, G. D. \& FACHEL, J. M. G., 2008, Biomonitoring of genotoxicity using mocronuclei assay in native population of Astianax jacuhiensis (Characiformes: Characidae) at sites under petrochemical influence. Sci Total Environ, 406: 337-343. doi:10.1016/j. scitotenv.2008.07.006.

LEMOS, C. T., RODEL, P. M., TERRA, N. T. \& ERDTMANN, B., 2001, Evaluation of basal micronucleus frequency and hexavalent chromium effects in fish erytrhrocytes. Environ. Toxicol. Chem., 20: 1320-1324. doi: 10.1002/etc.5620200621.
LEMOS, C. T., RODEL, P. M., TERRA, N. T., OLIVEIRA, N. C. D. \& ERDTMANN, B., 2007, River water genotoxicity evaluation using micronucleus assay in fish erythrocytes. Ecotoxicol. Environ Saf. 66: 391-401. doi:10.1016/j.ecoenv.2006.01.004.

LIMA, L. C., RIBEIRO, L. P., LEITE, R. C. \& CHEMIM, D., 2006, Estresse em Peixes. Rev. Bras. Reprod. Anim., 30: 113-117. Available from: www.cbra.org.br.

MATEUCA, R., LOMBAERT, N., AKA, P. V., DECORDIER, I. \& KIRSCH-VOLDERS, M., 2006, Chromosomal changes: induction, detection methods and applicability in human biomonitoring. Facets Environ. Nuclear Toxicol., 88: 1515-1531. doi:10.1016/j.biochi.2006.07.004.

PETRY, A. C. \& SCHULZ, U. H., 2000. Ritmo de alimentação de juvenis de Loricariichthys anus (Siluriformes, Loricariidae) da Lagoa dos Quadros, RS, Brasil. Iheringia, Ser. Zool., 89: 171-176.

RIBEIRO, L. R., SALVADORI, D. M. S. \& MARQUES, E. K., 2003, Mutagênese Ambiental. Canoas, Ed. ULBRA, 365p.

RUSSO, C., ROCCO, L., MORESCALCHI, M. A. \& STINGO, V., 2004, Assessment of environmental stress by the micronucleus test and the Comet assay on the genome of teleost populations from two natural environments. Ecotoxicol. Environ. Safety, 57: 168-174. doi:10.1016/S0147-6513(03)00027-7.

SÁNCHEZ-GALÁN, S., LINDE, A. R., IZQUIERDO, J. I. \& GARCÍA-VÁSQUEZ, E., 1998, Micronuclei and fluctuating asymmetry in brown trout (Salmo trutta): complementary methods to biomonitor freshwater ecosystems. Mutat. Res., 412: 219-225. doi:10.1016/S1383-5718(97)00186-1.

SCHULZ, U. H. \& MARTINS Jr., H., 2001, Astyanax fasciatus as bioindicator of water pollution of Rio dos Sinos, Brazil. Braz. J. Biol., 61: 615-621. doi: 10.1590/S1519-69842001000400010.

SILVA, J., ERDTMANN, B. \& HENRIQUES, J. A. P., 2003, Genética Toxicológica. Alcance, Porto Alegre, 424p.

SILVA, J., HERRMANN, S. M., HEUSER, V., PERES, W., POSSA MARRONI, N., GONZÁLEZ-GALLEGO, J. \& ERDTMANN, B., 2002, Evaluation of the genotoxic effect of rutin and quercetin by comet assay and micronucleus test. Food Chem. Toxicol., 40: 941-947. doi:10.1016/S0278-6915(02)00015-7.

SINGH, N. P. \& STEPHENS, R. E., 1997, Microgel electrophoresis: Sensitivity, mechanisms, and DNA electrostretching. Mutat. Res., 383: 167-175. doi:10.1016/S0921-8777(96)00056-0.

TAVARES-DIAS, M. \& MORAES, F. R., 2004, Hematologia de peixes teleósteos. Ribeirão Preto, VillimPress, 144p.

TICE, R. R., 1995, Applications of the single cell gel assay to environmental biomonitoring for genotoxic pollutants, pp. 69-79. In: B. E. Butterworth, L. D. Corkum \& J. Guzmán-rincón. (eds.), Biomonitors and Biomarkers as Indicators of Environmental Change. Plenum Press, New York.

WENDELAAR BONGA, S. E., 1997, The stress response in fish. Physiol. Rev. 77: 591-625.

ZAR, J. H., 1996, Biostatistical Analysis. Prentice-Hall Inc, New Jersey, EUA. 
